\title{
OPTIMIZATION OF SORBENT SYSTEM FROM PAPER MILL WASTE SHORT FIBERS FOR BIOREMEDIATION OF HEAVY HYDROCARBONS IN SOIL
}

\author{
S. Grigiškis ${ }^{1}$, E. Baškys ${ }^{1}$, D. Levišauskas ${ }^{2}$, M. Kavaliauskè ${ }^{1}$, \\ O. Dižavičienè ${ }^{1}$, J. Aikaitè-Stanaitiené ${ }^{1}$ \\ 1- JSC „Biocentras”, V. Graičiūno st. 10, 02241 Vilnius, Lithuania \\ Ph.: +37052661313, fax.: +37052602454, e-mail: biocentras@ biocentras.lt \\ 2- Process Control Department, Kaunas University of Technology \\ Studentų st. 50, 51368 Kaunas, Lithuania
}

\begin{abstract}
The aim was to develop a new improved Sorbent system $(S-S)$ from organic sorbent material, nutrients, biosurfactant and microbial cell producing it for bioremediation of heavy oil hydrocarbons in various soil types. New sorbent material (S-M) was developed from paper mill short waste fibers because it requires very low energy to manufacture and the production costs of this $S$ - $M$ is extremely low compared to similar products in the market. $S-M$ has good sorption characteristics for various oil products, is fully biodegradable, can be applied at sensitive environmental areas. $S-M$ can be combined with microorganisms producing biosurfactant. The goal of investigations was to optimize $S$-S composition to minimize the leakage of heavy hydrocarbons to deeper soil layers or ground water. The optimal composition of $S-S$ for all types of soil was determined: $S-M$ 86.3-89.3\%, microorganisms producing biosurfactant $\geq 10^{7}$ CFU/g, biosurfactant solution - 3\%, nutrients (nitrogen and phosphorous) 0.5 and 0.2\%. Recommended optimal S-S moisture is $7 \%$.
\end{abstract}

Keywords: sorbent system, oil bioremediation, heavy oil hydrocarbons, biosurfactant, optimization,.

\section{Introduction}

Environmental pollution with oil is very large problem all around the world, because oil is used in many industries. In fact, production and consumption of oil and petroleum products are increasing worldwide, and the risk of oil pollution is increasing accordingly. Most spills take place on land, and this accounts for a high volume of oil spilled. However, the cleanup is more difficult on land since soil has a tendency to absorb the oil leakage and only some biodegradation techniques are available for the clean up of oil from ground.

Therefore, the aim of this work is to develop and optimize novel cost-efficient Sorbent system (S-S) for soil remediation. S-S has be applied in-situ for heavy hydrocarbons treatment to reduce contaminant concentration to an acceptable level for starting up biodegradation process. This system is targeted to collection of oil products after spillage and for control of the hydrocarbons level in soil. So this integrated S-S effectively combines different soil remediation techniques for bringing the site back to acceptable environmental standards. Current sorbent market is very fragmented with different targeted applications and many products. Innovations are mainly related to development or selection of novel sorbent materials and targeted to make green and environmentally friendly products having sufficient functionalities. Common approaches are improvement of sorbent structure or adaptation of package for the more efficient oil degradation processes.

Although, it is not common practice to compose sorbent materials into systems, several types of sorbent systems are currently available consisting of different elements: sorbtic material and specific microbial strain [1,2], sorbtic material and specific microbial strain and fertilizers [3, 4], sorbtic materials and microbial cells producing bio-surfactants [5], sorbtic materials and the biosurfactant itself [6].

The great majorities of these sorbent systems are targeted to oil remediation in water environment $[1,3,4,6]$ and are not applicable in non-aqueous media. Although, combining 
different elements, some of them were investigated for oil remediation in non-aqueous media $[2,6]$, but commercially reliable results still have not been reported.

Whereas, the new developed S-S is based on low-cost natural organic sorbent material (S-M) developed from paper mill short fiber wastes and embedded with specific biosurfactant acting as activating agent for microorganisms producing more biosurfactant for further cleaning. Microorganisms are responsible for producing biosurfactant capable to separate the migration fraction of oil.

Surface active compounds embedded into S-M improve bioavailability of highly hydrophobic pollutants thus reducing surface tension and therefore enhancing both: solubility of heavy hydrocarbons in water and effect of sorption. Microorganisms start to produce biosurfactant, which begins to separate non-migration fraction of oil (which is strongly tied to soil), from soil binding it to S-M. The initial amount of biosurfactant acts as activating agent for removal soaked oil both from soil and from S-M, thus increasing bioavailability of hydrophobic compounds. Biosurfactant is also environmentally friendly, thus, does not cause any secondary contamination. Therefore, S-S presents unique and novel way of fast and effective reduction of pollution concentrations to required level for starting up enhanced bioremediation process. Nitrogen and phosphorus are added to the S-S in order to stabilize and preserve microorganisms producing biosurfactant.

The goal of experimental investigation was to optimize the composition of S-S elements in order to minimize the leakage of heavy hydrocarbons to deeper soil layers or ground water. For S-S development, optimal composition of soil treatment system had to be identified by defining the exact required amount of S-S elements. Since analysis of research results requiring large amounts of samples and equipment would have been comparatively expensive, computer modelling of the environmental processes has been selected as the best option. Computer modelling allows simulating physical and chemical processes in selected environment using selected parameters, being cost and time efficient as well as offering more flexibility of research that could be performed in comparison to other methods.

\section{1) Materials}

\section{Materials and methods}

Sorbent system components were used in the investigations: S-M, biosurfactant producing microbial culture, nutrients (nitrogen and phosphorus) and biosurfactant. Crude oil was used as heavy hydrocarbon pollutant in the experiments.

Sorbent material developed from paper mill short fiber wastes was used. Hydrocarbon sorption capacity of S-M was $4.3 \mathrm{~g}$ oil/g S-M.

Biosurfactant producing microbial culture and biosurfactant. Crude preparation of the biosurfactant was prepared by centrifugation of Arthrobacter $s p \mathrm{~N} 3$ strain culture liquid at $12000 \mathrm{rpm}$ for $20 \mathrm{~min}$. Arthrobacter sp N3 strain viable cell count of $8.4 \cdot 10^{8} \mathrm{CFU} / \mathrm{mL}$ was also measured in biosurfactant preparation.

Nutrients (Nitrogen and Phosphorus). Ammonium nitrate $\left(\mathrm{NH}_{4} \mathrm{NO}_{3}\right)$ was a source of nitrogen and dicalohydrogen phosphate $\left(\mathrm{K}_{2} \mathrm{HPO}_{4}\right)$ was source for phosphorus.

\section{2) Methods for optimization of SORBENT system composition}

The goal of optimization was to get the most effective S-S while changing its composition for two reasons: 1) that S-S could stop migration of oil contaminants in soil, and 2) to improve bio-accessibility of S-S to oil-oxidizing microorganisms that are used in decontamination technique of soil contaminated with heavy hydrocarbons.

The set of methods and procedures used for optimization of S-S composition is listed below. 


\section{Soil research and reaction surface methodology}

These procedures were applied to define optimal S-S composition for different types of soil. Soil texture was taken as a core soil property for investigations, as it affects the nature and extent of physical, chemical, and biological reactions. Investigations were based on the following assumptions: a) contaminants diffuse in soil from its top to the bottom; b) water sources are localized and protected, so the heavy hydrocarbons do not diffuse to these deep areas; c) biosurfactant initially embedded into S-M improves separation of heavy oil fractions from soil particles, and upgrades binding of this contaminant to oil-oxidizing microorganisms. Experiments were carried out in $10 \mathrm{~L}$ flowerpots, in which samples were taken from $3 \mathrm{~cm}, 8$ $\mathrm{cm}, 13 \mathrm{~cm}$ and $18 \mathrm{~cm}$ depth. In this model, length units are measured in centimeters, weight in milligrams, and time in days.

The optimization procedure refers to the reaction surface methodology. Six factorial experiment series were realized using close to D-optimal experimental design. Extra flowerpot was used for realization of repeated experiment to evaluate the reproducibility of experiments results (Table 1). The experiments were carried out for three different types of soil: loam, clay and sand.

Table 1.

Experimental design matrix with code $\left(x_{i}\right)$ and real $\left(X_{i}\right)$ variables for S-S elements

\begin{tabular}{|c|c|c|c|c|c|}
\hline \multirow{2}{*}{ No } & \multicolumn{2}{|c|}{$\begin{array}{c}\mathbf{X}_{\mathbf{1}} \\
\text { biosurfactant producing strain } \\
\text { N3 and biosurfactant [\%] }\end{array}$} & \multicolumn{2}{|c|}{$\begin{array}{c}\text { X } \\
\text { N : P [\%] }\end{array}$} & \multirow{2}{*}{ Depth [cm] } \\
\cline { 2 - 5 } & $\mathbf{X}_{\mathbf{1}}$ & $\mathbf{X 1}$ & $\mathbf{X}_{\mathbf{2}}$ & $\mathbf{X 2}$ & \\
\hline 1 & +1 & 5 & +1 & $0.5: 0.2$ & $3 / 8 / 13 / 18$ \\
\hline 2 & -1 & 1 & +1 & $0.5: 0.2$ & $3 / 8 / 13 / 18$ \\
\hline 3 & +1 & 5 & -1 & $0.1: 0.04$ & $3 / 8 / 13 / 18$ \\
\hline 4 & -1 & 1 & -1 & $0.1: 0.04$ & $3 / 8 / 13 / 18$ \\
\hline 5 & 0 & 3 & +1 & $0.5: 0.2$ & $3 / 8 / 13 / 18$ \\
\hline 6 & 0 & 3 & -1 & $0.1: 0.04$ & $3 / 8 / 13 / 18$ \\
\hline 7 & +1 & 5 & 0 & $0.3: 0.12$ & $3 / 8 / 13 / 18$ \\
\hline 8 & -1 & 1 & 0 & $0.3: 0.12$ & $3 / 8 / 13 / 18$ \\
\hline 9 & 0 & 3 & 0 & $0.3: 0.12$ & $3 / 8 / 13 / 18$ \\
\hline
\end{tabular}

Dried and riddled through sieve with $5 \mathrm{~mm}$ diameter holes, the clean soil was poured into the flowerpots up to the $0 \mathrm{~cm}$ line as compact as possible. To stimulate the interaction of pollutant with S-S, $1 \mathrm{~kg}$ of the same soil contaminated with crude oil $(200 \mathrm{~g} / \mathrm{kg})$ and the $5 \%$ or $10 \% \mathrm{~S}$ $\mathrm{S}$ added, was poured on the top of soil in flowerpots. The required amount of S-S was calculated according to concentration of pollution. Laboratory investigation results were used for identification of statistical models designed for prediction of migration of oil contaminants in the investigated types of soil at different amounts of S-S.

Biosurfactant producing microbial cell N3 and initial investigation range of the biosurfactant amount was $1-5 \%$ of amount of heavy hydrocarbons. Investigation range of the nitrogen amount was $0.1 \leq C_{\mathrm{N}} \leq 0.5 \%$ of amount of heavy hydrocarbons concentration, whereas phosphorus amount investigation range was $0.04 \leq C_{\mathrm{N}} \leq 0.2 \%$ of amount of heavy hydrocarbons contaminants concentration. Experiments were carried out at room temperature $\left(25 \pm 2{ }^{\circ} \mathrm{C}\right)$. Vertical migration of oil was evaluated after 1 and 5 days.

Calculations related to the process model identification and model-based optimization experiments were performed using Matlab/Simulink tools. Experimental data were used to identify parameter values of the statistical model (1), which was used to calculate the 
predicted responses corresponding to the results of six consecutive factorial experiments. The response surfaces are illustrated by isoresponse contour plots in Fig. 1.

Residual hydrocarbon mixtures in soil samples were determined by IR-spectrophotometry.

Evaluation of initial moisture content in Sorbent system. Investigations were carried out to evaluate values of S-S optimal moisture content, when system does not lose its sorbtic characteristics. Also S-S moisture had to be suitable for biosurfactant producing microorganisms' immobilization and had to be prepared easily and cost-effectively. During the investigations, sorbtic ability of S-S with different initial moisture content was evaluated.

Preparation of $S-S$ with different initial moisture. Dried S-S was sprayed with analytical water that S-S moisture would be 5\%;10\%;15\%;20\%;25\% and $30 \%$.

Sorption capacity tests under different S-S moisture levels were carried out. Method developed for the measurement of hydrocarbons sorption capacity by the S-S was based on ASTM F726-99: Standard Test Method for Sorbent Performance of Adsorbents.

Process optimization procedure

In this investigation, 4 steps experimental optimization procedure was applied. Detailed description of this procedure is presented below.

Step 1. Selection of initial composition of S-S using a priori knowledge about S-S components under optimization.

Step 2. Design and realization of statistical experiment in the selected area of S-S components concentration variations.

Step 3. Identification of statistical model for the response surface estimation. A second order polynomial model, which includes interaction term, was used to calculate the predicted response:

$$
Y=a_{0}+a_{1} \cdot x_{i}+a_{2} \cdot x_{j}+a_{11} \cdot x_{i}^{2}+a_{22} \cdot x_{j}^{2}+a_{12} \cdot x_{i} \cdot x_{j}
$$

Where $\mathrm{Y}$ - predicted response (hydrocarbons concentration); $\mathrm{xi}$ - independent variables (S-S components subjected to optimization); $\mathrm{n}$ - number of independent variables.

Parameters of the polynomial model (1) were identified using the least-squares method:

$$
\mathrm{A}=\left[\mathrm{F}^{\mathrm{T}} \mathrm{F}\right]^{-1} \mathrm{~F}^{\mathrm{T}} \mathrm{Y}
$$

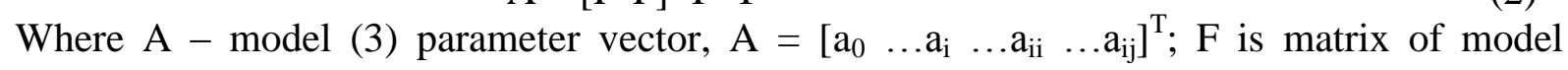
independent parameter values at factorial experiment.

Standard statistic tests were applied to evaluate adequacy of model and significance of model parameters.

Step 4. Model-based prediction of S-S composition point $\mathrm{x}^{*}=\left[\mathrm{x}_{1} * \ldots \mathrm{x}_{\mathrm{n}}{ }^{*}\right]^{\mathrm{T}}$, at which the minimum yield of hydrocarbon leakage with the particular S-S composition was obtained, and determination of optimal point location $[7,8 ; 9]$.

\section{Results and Discussion}

Sorbent system composition optimization in loam. Seven statistical models for S-S optimization with respect to detention of oil contaminants were identified. Experimental data were used to identify parameter values of the statistical model (1), which was used to calculate the predicted responses corresponding to the results of the factorial experiments. From the modeled response surfaces, it can be stated that to stop heavy hydrocarbons vertical migration, when $5 \% \mathrm{~S}$-S was used, optimal S-S components concentrations were: $\mathrm{X}_{1} \approx 3 \%$ and $\mathrm{X}_{2} \approx 0.5$. The same results of modeled response surfaces were, when $10 \%$ Sorbent was used, as optimal S-S components concentrations were $\mathrm{X}_{1} \approx 2.6(2.2 \div 3.0) \%$ and $\mathrm{X}_{2} \approx 0.5$.

Soil as not homogenous substrate determines wider dispersion of results when measuring the oil concentration in deeper layers. The calculated response surfaces, based on identified statistical models, demonstrated that predicted optimal value of $\mathrm{X}_{1}$ concentration was about $\mathrm{X}_{1}$ opt $\sim 3 \%$, the predicted optimal value of $\mathrm{X}_{2}$ for ground was outside the experimental design area, i.e., exceeds the value $0.5 \%$. However, taking into account that the soil is not homogenous substrate, it can be stated that $\mathrm{X}_{2} \mathrm{opt}$ is $0.5 \%$, i.e. S-S consisted of $3 \%$ of 
biosurfactant producing microorganisms' culture and biosurfactant (where amount of microorganisms was $\geq 10^{7} \mathrm{CFU} / \mathrm{g}$ ), $0.5 \%$ of ammonium and $0.2 \%$ of phosphorous.

Test experiments using $5 \%$ and $10 \%$ of S-S at the predicted optimal concentrations $\left(\mathrm{X}_{1}=3\right.$ $\%, \mathrm{X}_{2}=0.5$ ) confirmed the expected decrease of crude oil vertical migration (Fig. 1a). The oil concentration measurements were made after 5 days in $3 \mathrm{~cm}$ depth $(5 \% \mathrm{~S}-\mathrm{S})$ and after 1 day in $3 \mathrm{~cm}$ depth (10\% S-S, Fig. 1b). The results revealed that in the first case the predicted oil leakage was set at $56.9 \mathrm{mg} / \mathrm{kg}$, whereas experimentally achieved at $55.1 \mathrm{mg} / \mathrm{kg}$, so it can be stated that the model prediction well coincides with the experimental result. The same results were achieved in the second case, i.e. predicted by model minimal leakage was $61.2 \mathrm{mg} / \mathrm{kg}$, and $63.4 \mathrm{mg} / \mathrm{kg}$ was obtained in the control experiment.

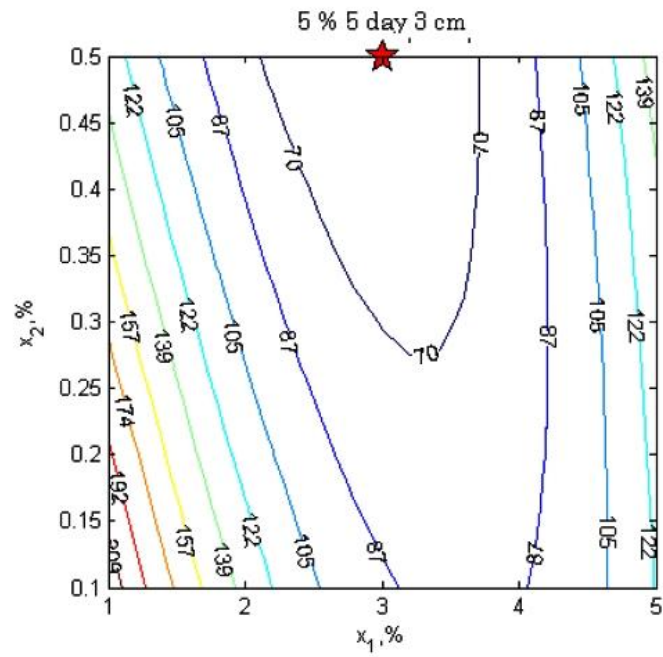

a)

\section{Fig. 1. Comparison of experiments result}

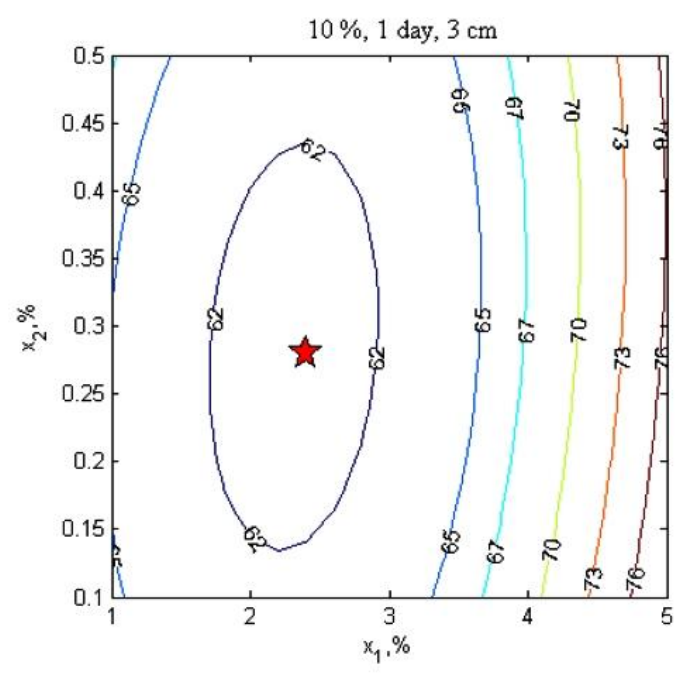

b) day, $3 \mathrm{~cm}$ )

Sorbent system composition optimization in clay. In clay for S-S optimization according to oil contaminants detention possibilities, ten statistically reliable models were made by the same procedure as previous.

The modeled response surfaces showed that after measurement of concentrations of vertically migrating oil contaminants in various depths, it can be concluded that with $5 \% \mathrm{~S}-\mathrm{S}$ the optimal component concentrations were $\mathrm{X}_{1} \approx 3 \%$ and $\mathrm{X}_{2}=0.2 \div 0.3(\approx 0.25 \%)$ after 1 day and $\mathrm{X}_{1} \approx 3 \%, \mathrm{X}_{2}=0.25 \div 0.35(\approx 0.3 \%)$ after 5 days.

The experiments results with $5 \% \mathrm{~S}-\mathrm{S}$ in deeper layers are more corrupted by random factors however the determined concentrations of S-S elements $\mathrm{X}_{1}$ and $\mathrm{X}_{2}$ are close to optimal (Fig. 2a). Even more, for both type substrates - loam or clay, the optimal concentrations are very close.

The calculated response surfaces show that the predicted optimal value of $\mathrm{X}_{1}$ concentration is $\mathrm{X}_{1} \mathrm{opt}=3 \%$, the predicted optimal value of $\mathrm{X}_{2}$ for clay is $\mathrm{X}_{2} \mathrm{opt}=0.3 \%$, i.e. S-S consist of 3 $\%$ biosurfactant producing microorganisms culture and biosurfactant (where amount of microorganisms was $\geq 10^{7} \mathrm{CFU} / \mathrm{g}$ ), $0.3 \%$ of ammonium and $0.12 \%$ of phosphorous.

Test experiments using $5 \%$ and $10 \%$ of S-S at the predicted optimum $\left(\mathrm{X}_{1}=3 \%, \mathrm{X}_{2}=0.3\right)$ confirmed the expected decrease of vertical crude oil migration (Fig. 2b). Oil concentration measurements were performed after 1 and 5 days in $3 \mathrm{~cm}$ depth and in $8 \mathrm{~cm}$ depth when $10 \%$ $\mathrm{S}-\mathrm{S}$ was used. The results showed that in the first case, forecasted oil leakage was $45.7 \mathrm{mg} / \mathrm{kg}$ after 1 day and $64.2 \mathrm{mg} / \mathrm{kg}$ after 5 days, whereas experimentally calculated results were also very close -43.7 and $67.2 \mathrm{mg} / \mathrm{kg}$. In the second case, analogues results were achieved. Minimal leakage was $5.76 \mathrm{mg} / \mathrm{kg}$ and $23.5 \mathrm{mg} / \mathrm{k}$ (after 1 and 5 days), and during the repeated 
experiment vertically leaked oil concentration in $8 \mathrm{~cm}$ depth was $5.94 \mathrm{mg} / \mathrm{kg}$ and $21.3 \mathrm{mg} / \mathrm{kg}$, respectively.
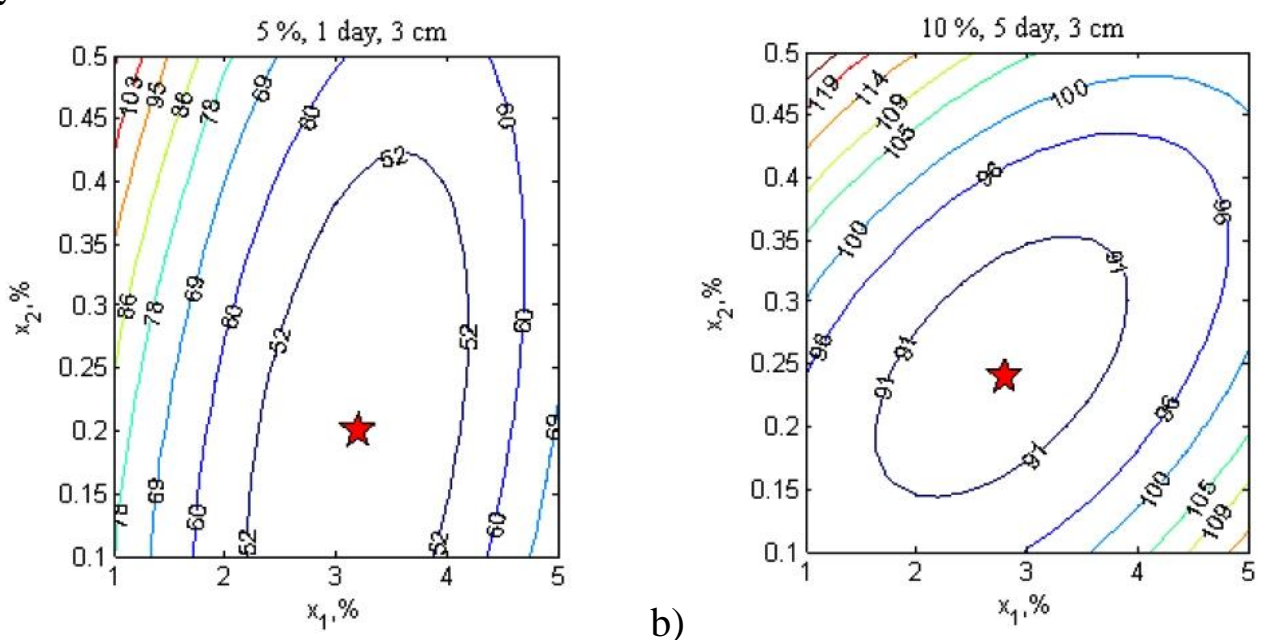

a)

Fig. 2. Comparison of experiments results (a) $5 \% \mathrm{~S}-\mathrm{S}, \mathbf{1}^{\text {st }} \mathrm{day}, 3 \mathrm{~cm}$; b) $10 \% \mathrm{~S}-\mathrm{S}, 5^{\text {th }}$ day, $3 \mathrm{~cm}$ )

Sorbent system composition optimization in sand. In sand for S-S optimization according to oil contaminants detention possibilities, five statistically reliable models were made by the same procedure as previous. When oil concentration was measured in deeper layers wider data scatter was observed, which was caused by not homogenous substrate - sand.

Test experiments with $5 \%$ and $10 \%$ of S-S at the predicted optimal conditions $\left(\mathrm{X}_{1}=3 \%, \mathrm{X}_{2}\right.$ $=0.4 \%$ ) confirmed the expected decrease of the vertical crude oil migration (Fig. 3a, Fig. $3 b)$. The crude oil vertical flow rate decreased 3.8 times in $3 \mathrm{~cm}$ depth using $5 \%$ and 4.8 times using $10 \%$ of $\mathrm{S}-\mathrm{S}$ at the same depth, compared to that obtained at conditions corresponding to the center point of factorial experiments.

The calculated response surface, demonstrate, that the predicted optimal value of the $X_{1}$ concentration is $\mathrm{X}_{1} \mathrm{opt}=3 \%$, and the predicted optimal value of $\mathrm{X}_{2}$ for clay is $\mathrm{X}_{2} \mathrm{opt}=0.4 \%$, i.e. S-S consisted of $3 \%$ biosurfactant producing microorganisms culture and biosurfactant (where amount of microorganisms was $\geq 10^{7} \mathrm{CFU} / \mathrm{g}$ ), $0.3 \%$ of ammonium and $0.16 \%$ of phosphorous.

The results show that the predicted oil leakage is $330 \mathrm{mg} / \mathrm{kg}$ (after 1 day in $3 \mathrm{~cm}$ depth with 5 $\% \mathrm{~S}-\mathrm{S}$ ) and $229 \mathrm{mg} / \mathrm{kg}$ (after 5 days in $3 \mathrm{~cm}$ depth with $10 \% \mathrm{~S}-\mathrm{S}$ ), during the repeated experiment vertically leaked crude oil concentration results were also very close -224 and $234 \mathrm{mg} / \mathrm{kg}$ respectively. These results showed that forecasted model results coincided with experimental.

a)

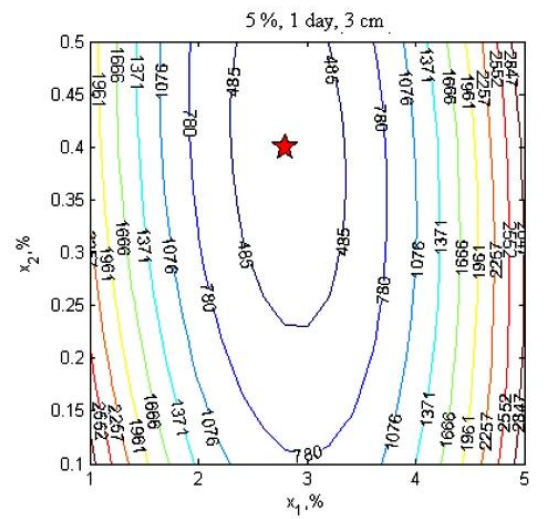

b)

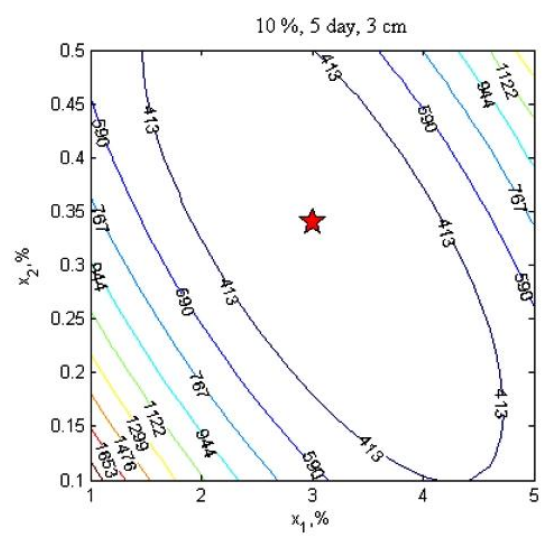

Fig. 3. Comparison of experiments results (a) $5 \% \mathrm{~S}-\mathrm{S}, 1^{\text {st }}$ day, $3 \mathrm{~cm}$; b) $10 \% \mathrm{~S}-\mathrm{S}, 5^{\text {th }}$ day, $\left.3 \mathrm{~cm}\right)$ 


\section{Evaluation of initial moisture content in Sorbent system}

Too wet or too dry sorbtic material makes unfavorable medium for biosurfactant producing microorganisms' culture. That is why optimal level of moisture is required to keep stable amount of vital microbial cells producing biosurfactant. Therefore, it was necessary to determine the optimal initial S-S moisture. Investigations showed that with $5 \%$ of initial S-S moisture S-S loses $5.20 \%$ of sorbtic capability, whereas with initial $10 \%$ of S-S moisture up to $16 \%$ (Fig. 4 ).

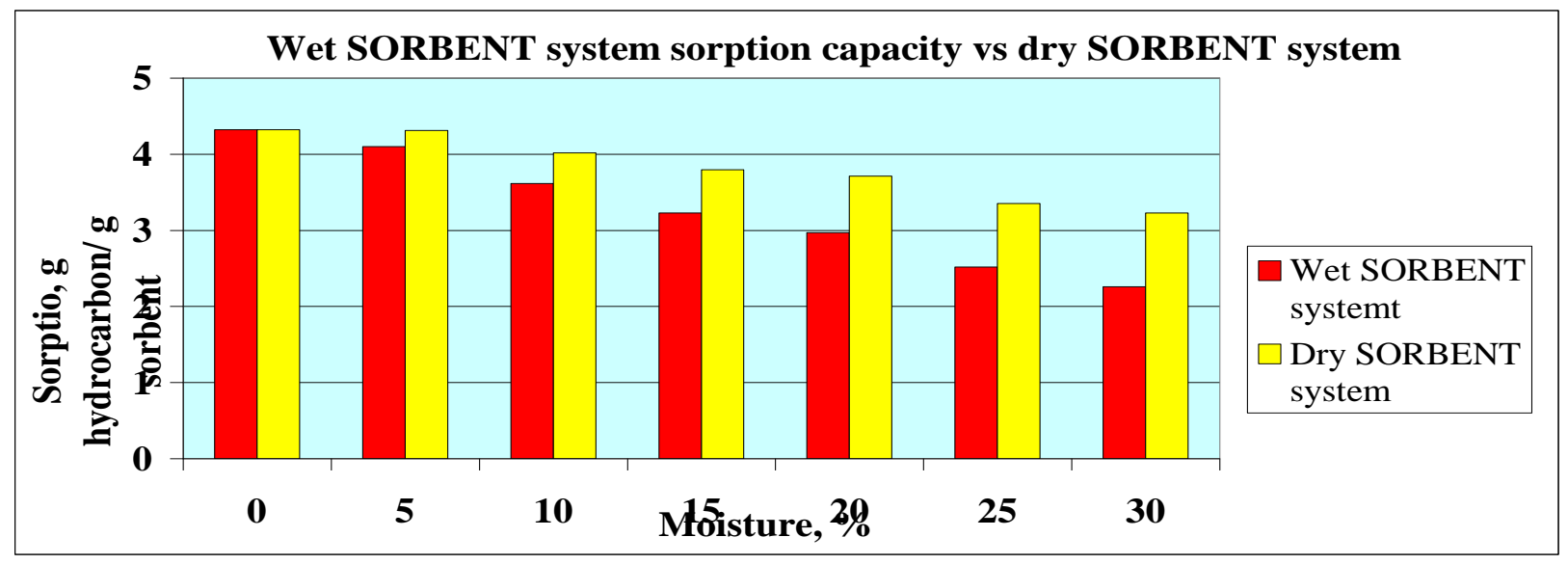

Fig. 4. Dependence of S-S sorbtic capability from initial moisture content in S-S

As it is shown in Fig. 4, when the initial S-S moisture increased, its sorbtic capabilities decreased. According the research results, recommended optimal S-S moisture is $7 \%$, and it should not exceed $10 \%$.

\section{Optimum Sorbent system composition}

In loam and clay systems optimal composition of S-S reduced vertical oil contaminants migration in $8 \mathrm{~cm}$ depth up to 3-5 times, whereas in sand - approximately 10 times compared to when only S-M alone was used. Compared to when no S-M was used to stop vertical oil contaminants migration, S-S reduced vertical oil migration up to 10 times in loam and clay, whereas in sand - up to 30 times, when initial oil contaminants concentration was the same $200 \mathrm{~g} / \mathrm{kg}$.

Identical experimental design procedure was used to optimize the amounts of S-S components. In all types of soil (loam, clay and sand) modeled reaction surfaces and concentrations of oil that migrated vertically in various depths showed that with $5 \%$ and with $10 \%$ of S-S used for heavy hydrocarbons degradation, optimal concentrations of its components were very similar.

Repeated experiment system composition and achieved results were approved - following optimum composition for all types of soil was determined: S-M 86.3-89.3\%, microorganisms producing biosurfactant $\geq 10^{7} \mathrm{CFU} / \mathrm{g}$, initial amount of biosurfactant $-3 \%$, nutrients, such as nitrogen and phosphorous 0.5 and $0.2 \%$, additionally.

\section{Conclusions}

Four components required in the sorbent system are indentified: sorbent material, biosurfactant producing microbial culture, nutrients ( $\mathrm{N}$ and $\mathrm{P}$ ) and biosurfactant.

In various depths of vertically migrated oil concentrations treated with $5 \%$ and $10 \%$ of Sorbent system used for heavy hydrocarbons degradation, optimal concentrations of Sorbent system components were very similar in all types of soil (loam, clay and sand). Using computer modeling it was determined that the initial amount of biosurfactant and microorganisms' producing it has to be $3 \%$ (where amount of microorganisms was $\geq 10^{7}$ $\mathrm{CFU} / \mathrm{g})$. 


\section{Grigiškis S., Baškys E., Levišauskas D., Kavaliauskė M., Dižavičienė O., Aikaitė-Stanaitienė J. OPTIMIZATION OF SORBENT SYSTEM FROM PAPER MILL WASTE SHORT FIBERS FOR BIOREMEDIATION OF HEAVY HYDROCARBONS IN SOIL}

Optimal amount of nutrients in S-S after computer modeling was determined at $0.5 \%$ of nitrogen and $0.2 \%$ of phosphorous.

Also it was determined that it is necessary to keep enough amount of biosurfactant producing microorganisms' vital cells immobilized on S-M with required moisture level. Therefore, recommended optimal S-S moisture is $7 \%$, and it should not exceed $10 \%$.

Therefore, very novel and optimized S-S was developed, combining different elements that allow S-S to solve environmental problems of heavy oil pollution, especially in soil, by being both: very efficient and made from inexpensive natural components. As investigations revealed that depending on type of soil, S-S can reduce vertical oil migration up to 30 times with initial $200 \mathrm{~g} / \mathrm{kg}$ oil concentration.

\section{Acknowledgments}

This paper reflects findings from EU funded $7^{\text {th }}$ Framework program project "SORBENT" (232533).

\section{Summary}

Novel Sorbent system was developed and optimized for application in-situ for heavy hydrocarbons treatment in various soil types. Sorbent system is based on low-cost natural organic sorbent material developed from paper mill short fiber wastes and embedded with specific biosurfactant acting as activating agent for microorganisms producing more biosurfactant for further cleaning. During the investigations composition of S-S elements was optimized in order to minimize the leakage of heavy hydrocarbons to deeper soil layers or ground water.

\section{References}

1. Setti, L., Mazzieri, S., Pifferi, P. G. 1999. Enhanced degradation of heavy oil in an aqueous system by a Pseudomonas sp. in the presence of natural and synthetic sorbents. Bioresource Technology, 67(2), 191199.

2. Suni, S., Kosunen, A. L., Romantschuk M. Microbially Treated Peat-Cellulose Fabric as a Biodegradable Oil-Collection Cloth. Journal of Environmental Science and Health, Part A: Toxic/Hazardous Substances and Environmental Engineering, 1532-4117, Volume 41, Issue 6, 2006, Pages 999 - 1007.

3. Gertler, C., Gerdts, G., Timmis, K.N., Golyshin, P.N. Microbial consortia in mesocosm bioremediation trial using oil sorbents, slow-release fertilizer and bioaugmentation. FEMS microbiology ecology, Vol. 69, No. 2, Aug 2009, pp. 288-300.

4. Gertler, C., Gerdts, G., Timmis, K.N., Yakimov, M.M., Golyshin, P.N. Populations of heavy fuel oildegrading marine microbial community in presence of oil sorbent materials. Journal of applied microbiology, Vol. 107, No. 2, Aug 2009, pp. 590-605.

5. Biswas S., Chaudhari S. K., Mukherji S. (2005). Microbial uptake of diesel oil sorbed on soil and oil spill clean-up sorbents. Chem Technol Biotechnol 80:587-593.

6. Martha, D., Mulligan C.N. Rhamnolipid Biosurfactant Assisted Dispersion and Biodegradation of Spilled Oil on Surface Waters. Paper presented at the 2005 Proceedings, Annual Conference - Canadian Society for Civil Engineering, 10 p. 2005.

7. Montgomery, D.C. 2008. Design and Analysis of Experiments. John Wiley\&Sons. P. 680.

8. Myers, R.H, Montgomery, D.C. 2002. Response Surface Methodology, Process and Product optimization Using Designed Experiments. John Wiley \& Sons, 798 p.

9. Theodore, R., Panda, T. 1995. Application of response surface methodology to evaluate the influence of temperature and initial $\mathrm{pH}$ on the production of beta $-1,3$ glucanase and carboxymetyl cellulose from Trichoderma harzianum. Enzyme Microb. Technol, 17, 1043-1049. 